\title{
Ulinastatin administration is associated with a lower incidence of acute kidney injury after cardiac surgery: a propensity score matched study
}

\author{
Xin Wan ${ }^{1+}$, Xiangcheng Xie ${ }^{2+}$, Yasser Gendoo ${ }^{1}$, Xin Chen ${ }^{3}$, Xiaobing $\mathrm{Ji}^{1}$ and Changchun Cao ${ }^{1 *}$
}

\begin{abstract}
Background: Systemic inflammation is involved in the development of acute kidney injury (AKI) after cardiac surgery with cardiopulmonary bypass (CPB). Ulinastatin, a urinary trypsin inhibitor (UTI), possesses a variety of antiinflammatory effects. Therefore, we hypothesized that the administration of ulinastatin would reduce the occurrence of AKI in patients undergoing cardiac surgery with CPB.

Methods: A retrospective propensity score matched analysis was used to evaluate the effect of ulinastatin on the development of AKI in patients undergoing first documented cardiac surgery with CPB between January 2008 and December 2012 in our hospital. Multiple logistic regression models were also employed to identify the association between UTI administration and development of AKI.
\end{abstract}

Results: A total of 2072 patients who underwent cardiac surgery with CPB met the inclusion criteria. Before propensity score matching, variables such as age, baseline creatinine, CPB duration, red blood cells transfused, and hematocrit were statistically different between the ulinastatin (UTI) group and the control group. On the basis of propensity scores, 409 UTI patients were successfully matched to the 409 patients from among those 1663 patients without UTI administration. After propensity score matching, no statistically significant differences in the baseline characteristics were found between the UTI group and the control group. The propensity score matched cohort analysis revealed that AKI and the need for renal replacement therapy occurred more frequently in the control group than in the UTI group ( $40.83 \%$ vs. $30.32 \%, P=0.002 ; 2.44 \%$ vs. $0.49 \%, P=0.02$, respectively). However, there were no significant differences in mortality, length of intensive care unit stay, and length of hospital stay between the UTI group and the control group. Using multivariate logistic regression analysis, we found ulinastatin played a protective role in the development of AKI after cardiac surgery (odds ratio $0.71,95 \%$ confidence interval $0.56-0.90, P=0.005$ ).

Conclusions: This study shows that ulinastatin was associated with a lower incidence of AKI after cardiac surgery, suggesting that the administration of ulinastatin may be favorable for those patients undergoing cardiac surgery with $\mathrm{CPB}$.

Keywords: Acute kidney injury, Ulinastatin, Cardiac surgery, Cardiopulmonary bypass

\footnotetext{
* Correspondence: changchuncao@yeah.net

${ }^{\dagger}$ Equal contributors

'Department of Nephrology, Nanjing First Hospital, Nanjing Medical

University, 68 Changle Road, Nanjing, Jiangsu 210006, China

Full list of author information is available at the end of the article
}

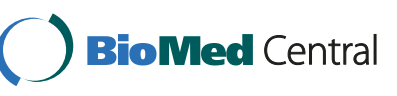

C 2016 Wan et al. Open Access This article is distributed under the terms of the Creative Commons Attribution 4.0 International License (http://creativecommons.org/licenses/by/4.0/), which permits unrestricted use, distribution, and reproduction in any medium, provided you give appropriate credit to the original author(s) and the source, provide a link to the Creative Commons license, and indicate if changes were made. The Creative Commons Public Domain Dedication waiver (http://creativecommons.org/publicdomain/zero/1.0/) applies to the data made available in this article, unless otherwise stated. 


\section{Background}

Acute kidney injury (AKI) commonly occurs in patients undergoing cardiac surgery, especially those treated with cardiopulmonary bypass (CPB) [1]. The incidence of cardiac surgery-associated (CSA) AKI ranges from $8.9 \%$ [2] to $39 \%$ [3], depending on the definition used. Renal replacement therapy (RRT) is needed in $1-5 \%$ of patients [4], and the mortality rate is $1.4 \%$ [5]. Previous studies demonstrated that even mild elevation in serum creatinine $(\mathrm{SCr})$ levels after cardiac surgery is significantly associated with higher mortality [6-8]. However, the treatment for CSA-AKI still remains challenging [9]; thus, prevention is the mainstay of effective treatment for patients at high risk of developing AKI.

There are multiple factors involved in the development of CSA-AKI, including hemodynamic, inflammatory, metabolic, and nephrotoxic factors [10]. Emerging evidence shows that systemic inflammation plays a key role in the development of CSA-AKI and participates in renal injury, especially tubular lesions [11-15].

To date, pharmacological renal protection strategies remain limited [16]. Ulinastatin, a urinary trypsin inhibitor (UTI) that inhibits various inflammatory proteases, including chymotrypsin, trypsin, and neutrophil elastase, has been widely used in China, Japan, and Korea for the treatment of patients with inflammatory disorders, postoperative organs protection, shock, and pancreatitis [17-19]. A previous study has shown that ulinastatin can decrease cytokine concentrations in patients undergoing cardiac surgery [20].

However, studies investigating its renoprotective role in the development of AKI in patients undergoing cardiac surgery with CPB are limited [21]. Thus, the aim of the present study was to test the hypothesis that the administration of ulinastatin would reduce the incidence of CSA-AKI.

\section{Methods \\ Patients}

This retrospective study included patients aged 18 years or older who underwent cardiac procedures with $\mathrm{CPB}$ at the Nanjing First Hospital in Nanjing, China, between January 2008 and December 2012. A total of 2072 patients were selected for analysis. Patients with end-stage kidney disease needing RRT before surgery were excluded.

This study was performed in accordance with the Declaration of Helsinki and was approved by the Regional Human Research Ethics Committee of Nanjing First Hospital (reference 201409-1). Individual patient consent was waived on condition that all patient data were deidentified before analysis, because this study was a retrospective analysis. The most recent examined $\mathrm{SCr}$ value within 7 days before surgery was defined as the baseline creatinine level.

\section{Anesthesia}

Patients were premedicated with intramuscular morphine $0.2 \mathrm{mg} / \mathrm{kg}$ and scopolamine $0.3 \mathrm{mg}$. Anesthesia induction was performed with midazolam $0.2 \mathrm{mg} / \mathrm{kg}$, fentanyl $10 \mu \mathrm{g} / \mathrm{kg}$, and vecuronium $0.15 \mathrm{mg} / \mathrm{kg}$, and then tracheal intubation was performed. Anesthesia was maintained with continuous propofol $(4-8 \mathrm{mg} / \mathrm{kg} / \mathrm{h})$ and intermittent intravenous fentanyl, midazolam, vecuronium, and inhalation of 1-2 \% isoflurane. Right internal jugular vein was cannulated for transfusion. Electrocardiography, central venous pressure, mean arterial pressure (MAP), arterial oxygen saturation, and nasopharynx and rectal temperature were monitored.

\section{Ulinastatin administration}

Patients who were prescribed with and without ulinastatin were identified and correspondingly divided into the UTI group and the control group. Patients in the UTI group received a bolus dose of ulinastatin 500,000 KIU intravenously in $50 \mathrm{ml}$ of saline for 15 minutes after induction of anesthesia.

\section{Anticoagulation}

The dose of unfractionated heparin via central venous catheter used for anticoagulation during CPB was 300$400 \mathrm{U} / \mathrm{kg}$ plus additional doses to achieve and maintain an activated clotting time between 480 and 600 seconds. Protamine sulfate was used to reverse heparin-induced anticoagulation after separation from CPB.

\section{CPB management and surgical procedures}

The CPB circuit was primed with a solution containing $500 \mathrm{ml}$ of crystalloid solution, $1000 \mathrm{ml}$ of hydroxyethyl starch, and $200 \mathrm{ml}$ of $20 \%$ mannitol. Management of $\mathrm{CPB}$ included alpha-stat $\mathrm{pH}$ management, MAP in the range of $50-80 \mathrm{mmHg}$, hematocrit of $20-25 \%$, and a non-pulsatile flow rate of $2.0-2.4 \mathrm{~L} / \mathrm{min} / \mathrm{m}^{2}$. The surgical procedures included coronary artery bypass grafting, mitral valve replacement, mitral and aortic valve replacement, and aortic valve replacement.

\section{Data collection}

The demographic, preoperative, intraoperative, and postoperative data were collected from an electronic medical record database. $\mathrm{SCr}$ was recorded each day until the seventh day after surgery. Urine output data were not collected, owing to absence of these data in the records.

\section{Outcome endpoint}

The primary endpoints were set as CSA-AKI, which was defined using Kidney Disease: Improving Global Outcomes criteria as an increase in $\mathrm{SCr} \geq 0.3 \mathrm{mg} / \mathrm{dl}$ $(\geq 26.5 \mu \mathrm{mol} / \mathrm{L})$ within $48 \mathrm{~h}$, and an increase in $\mathrm{SCr}$ to $\geq 1.5$ times baseline known or presumed to have 
occurred within the prior 7 days. Overall mortality, need for RRT, intensive care unit (ICU) length of stay, and hospital length of stay were also recorded.

\section{Assessment of adverse events}

Adverse events associated with ulinastatin, such as nausea, vomiting, leukocytopenia, hypersensitivity reactions, and elevation of transaminase, were recorded.

\section{Statistical methods}

The data were analyzed using SPSS version 18.0 software (SPSS, Chicago, IL, USA) and the MatchIt package in $\mathrm{R}$ (version 2.8.1; http://www.r-project.org/). Continuous variables following a normal distribution were expressed as mean \pm standard deviation, and categorical variables were expressed as percentages. An unpaired $t$ test was employed to compare means between two groups. The $x^{2}$ test or Fisher's exact test was used to compare categorical variables between two groups of subjects. The Mann-Whitney $U$ test was used to compare medians. Multiple regression binary logistic regression with the backward stepwise method was performed to evaluate the relationship between the administration of ulinastatin and the occurrence of AKI. The significant acceptance and removal levels for a covariate were set at 0.05 and 0.1 , respectively. Data were listed as odds ratios (ORs) with $95 \%$ confidence intervals (CIs). Adjusted variables were age, sex, body mass index (BMI), history of hypertension, history of diabetes, insulin-controlled diabetes, chronic obstructive pulmonary disease (COPD), chronic kidney disease, cerebrovascular disease, MAP, history of coronary angiography, ejection fraction, preoperative baseline creatinine level, hematocrit, red blood cells (RBCs) transfused, $\mathrm{CPB}$ duration, body temperature $\left(>38^{\circ} \mathrm{C}\right)$ after surgery within 3 days, and mechanical ventilation time.

\section{Propensity score matching}

Propensity scores for each subject were generated using a multivariable logistic regression analysis model to compute the probability of ulinastatin administration based on the following covariates: age, sex, BMI, diabetes, insulin-controlled diabetes, hypertension, COPD, chronic kidney disease, cerebrovascular disease, coronary angiography, preoperative baseline creatinine level, CPB duration, MAP, erythrocyte transfusion, ejection fraction, history of coronary angiography, hematocrit, and mechanical ventilation. Propensity scores were then employed to create 1:1 matched pairs (matching the UTI users to non-UTI users) using a nearest neighbor matching algorithm without a caliper method.

\section{Results}

Patient characteristics

A total of 2072 patients who underwent cardiac surgery with $\mathrm{CPB}$ met the inclusion criteria. Characteristics of the study subjects before and after propensity score matching are listed in (Table 1). Age, baseline creatinine, $\mathrm{CPB}$ duration, $\mathrm{RBCs}$ transfused, and hematocrit were statistically different between the UTI and control groups. On the basis of the propensity score, 409 patients who received UTI were successfully matched to 409 patients who did not have the UTI treatment (Fig. 1). After propensity score matching, no statistically significant baseline characteristics between the UTI group and the control group were found.

\section{Comparison of patient outcomes}

Cohort analysis revealed that AKI and RRT occurred more frequently in the control group (40.83\% vs. $30.32 \%$, $P=0.002 ; 2.44 \%$ vs. $0.49 \%, P=0.02$, respectively) (Fig. 2 ). No statistically significant differences in ICU length of stay, in-hospital length of stay, and mortality were found between the control group and the UTI group $(P>0.05)$ (Table 2).

\section{Ulinastatin administration is a protective factor in the development of AKI}

Multivariate logistic regression analysis was used to determine the possible protective role of ulinastatin in the development of AKI. The results are listed in Table 3. Notably, the administration of ulinastatin was found to be beneficial for protecting against CSA-AKI development (OR 0.71, $95 \%$ CI 0.56-0.90, $P=0.005$ ). The independent risk factors for CSA-AKI were as follows: male sex (OR 1.36, $95 \%$ CI 1.12-1.66, $P=0.002$ ), BMI (OR 1.28 , $95 \%$ CI $1.10-1.48, P=0.001)$, history of hypertension (OR 1.58, $95 \%$ CI 1.23-1.96, $P<0.001$ ), insulindependent diabetes mellitus (OR 1.59, 95 \% CI 1.07-2.35, $P=0.021$ ), CPB duration $\geq 110$ minutes (OR 1.38, $95 \% \mathrm{CI}$ $1.13-1.68, P=0.001)$, body temperature $\left(>38^{\circ} \mathrm{C}\right)$ after surgery within 3 days (OR 1.22, $95 \%$ CI 1.016-1.49, $P=$ 0.044), RBC units transfused (OR 1.09, $95 \%$ CI 1.06-1.12, $P<0.001$ ), and mechanical ventilation time $\geq 9$ h (OR 1.01, 95 \% CI 1.00-1.02, $P=0.007)$.

\section{Assessment of adverse events}

No adverse events associated with UTI were found.

\section{Discussion}

In the present study, we investigated the role of ulinastatin in the occurrence of AKI in patients undergoing cardiac surgery with $\mathrm{CPB}$. Using a propensity score matching method, we found that patients receiving UTI treatment had a significantly lower incidence of AKI than those in the control group ( $30.32 \%$ vs. $40.83 \%, P=0.002)$. Multivariate logistic regression analysis also revealed that ulinastatin played a beneficial role in the development of AKI. The independent risk factors found in our study, such as history of hypertension, insulin dependent diabetes, 
Table 1 Baseline characteristics of subjects before and after propensity score matched analysis

\begin{tabular}{|c|c|c|c|c|c|c|}
\hline \multirow[t]{2}{*}{ Variable } & \multicolumn{3}{|c|}{ Before matching } & \multicolumn{3}{|c|}{ Propensity score matched } \\
\hline & $\begin{array}{l}\text { Control group } \\
(n=1663)\end{array}$ & $\begin{array}{l}\text { UTI group } \\
(n=409)\end{array}$ & $P$ value & $\begin{array}{l}\text { Control group } \\
(n=409)\end{array}$ & $\begin{array}{l}\text { UTI group } \\
(n=409)\end{array}$ & $P$ value \\
\hline Age, yr & $56 \pm 13$ & $54 \pm 14$ & 0.008 & $54 \pm 14$ & $54 \pm 14$ & 0.880 \\
\hline Male sex, $n(\%)$ & $883(53)$ & $234(57)$ & 0.135 & $235(57.45)$ & $234(57.21)$ & 0.944 \\
\hline $\mathrm{BMI}, \mathrm{kg} / \mathrm{m}^{2}$ & $23.6 \pm 3.6$ & $23.4 \pm 3.6$ & 0.315 & $23.5 \pm 3.7$ & $23.4 \pm 3.6$ & 0.757 \\
\hline History of hypertension, $n(\%)$ & $581(36)$ & $125(31)$ & 0.094 & $119(29.1)$ & $125(30.6)$ & 0.647 \\
\hline History of diabetes mellitus, $n(\%)$ & $175(10.5)$ & $40(9.8)$ & 0.315 & $44(10.8)$ & $40(9.8)$ & 0.363 \\
\hline Insulin-controlled diabetes, $n$ (\%) & $99(6.0)$ & $26(6.4)$ & 0.563 & $27(6.6)$ & $26(6.4)$ & 0.887 \\
\hline COPD, $n(\%)$ & $27(1.6)$ & $11(2.7)$ & 0.150 & $9(2.2)$ & $11(2.7)$ & 0.490 \\
\hline Chronic kidney disease, $n$ (\%) & $30(1.8)$ & $5(1.2)$ & 0.414 & $3(0.73)$ & $5(1.2)$ & 0.722 \\
\hline Cerebrovascular disease, $n$ (\%) & $80(4.8)$ & $15(3.7)$ & 0.322 & $14(3.4)$ & $15(3.7)$ & 0.850 \\
\hline Coronary angiography, n (\%) & $590(35.5)$ & $150(36.7)$ & 0.651 & $165(40.3)$ & $150(36.7)$ & 0.281 \\
\hline Ejection fraction, \% & $59.2 \pm 8.4$ & $59.1 \pm 9.4$ & 0.953 & $58.9 \pm 8.7$ & $59.1 \pm 9.4$ & 0.761 \\
\hline Creatinine, $\mu \mathrm{mol} / \mathrm{L}$ & $75.0 \pm 33.3$ & $82.4 \pm 26.9$ & $<0.001$ & $82.9 \pm 53.9$ & $82.4 \pm 26.9$ & 0.889 \\
\hline CPB duration, min & $112.9 \pm 48.0$ & $106.3 \pm 42.0$ & 0.006 & $103.2 \pm 40.2$ & $106.3 \pm 42.0$ & 0.285 \\
\hline MAP, $\mathrm{mmHg}$ & $62.3 \pm 7.3$ & $62.1 \pm 5.6$ & 0.515 & $62.2 \pm 7.8$ & $62.1 \pm 5.6$ & 0.803 \\
\hline RBCs transfused, $U$ & $4.3 \pm 4.2$ & $5.8 \pm 4.9$ & $<0.001$ & $5.3 \pm 5.3$ & $5.8 \pm 4.9$ & 0.241 \\
\hline Hematocrit, \% & $23.4 \pm 4.6$ & $25.0 \pm 5.6$ & $<0.001$ & $25.1 \pm 5.3$ & $25.0 \pm 5.6$ & 0.736 \\
\hline Mechanical ventilation, median (range) & $7.8(5.5-10.6)$ & $7.8(5.9-11.2)$ & 0.073 & $7.8(5.2-11.7)$ & $7.8(5.9-11.2)$ & 0.078 \\
\hline
\end{tabular}

Abbreviations: $B M I$ body mass index, $C P B$ cardiopulmonary bypass, MAP mean arterial pressure, COPD chronic obstructive pulmonary disease, UTI urinary trypsin inhibitor, $R B C s$ red blood cells

mechanical ventilation, $\mathrm{CPB}$ duration, and erythrocyte transfusion, were in accord with a previous study [9], while early postoperative fever $\left(>38^{\circ} \mathrm{C}\right.$ in the first $\left.72 \mathrm{~h}\right)$, which is rarely caused by an infection [22], was found for the first time (to the best of our knowledge) to be an independent risk factor for CSA-AKI. The underlying mechanism was thought to be related to systemic inflammatory responses, which is one of the postoperative complications in patients undergoing cardiac surgery with $\mathrm{CPB}$ [23].

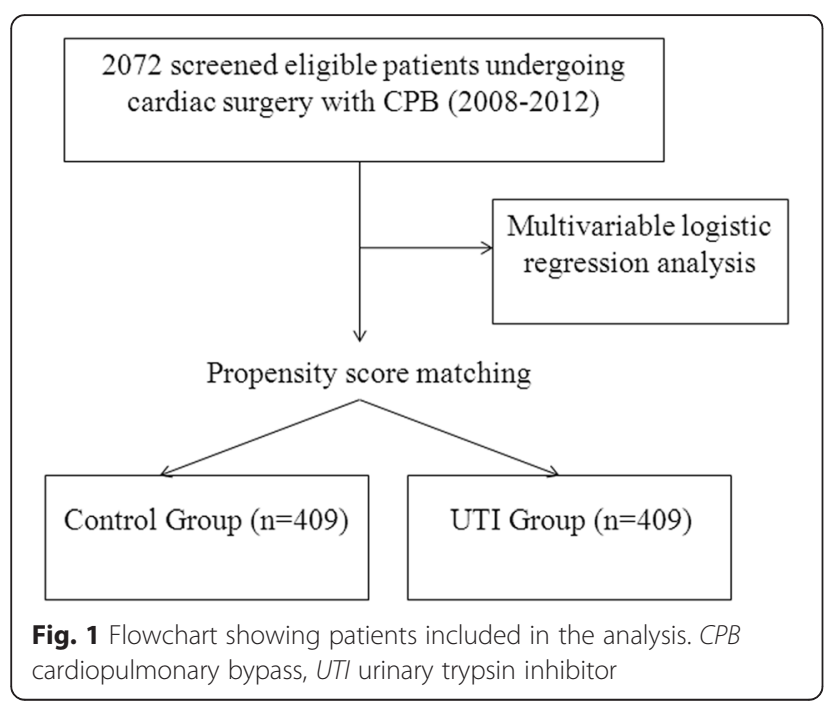

These findings may be of importance in light of the renal protection in this setting due to CSA-AKI being significantly associated with higher postoperative mortality [8].

Systemic inflammatory response syndrome caused by cardiac surgery was found to play a central role in the development of AKI $[24,25]$ by deteriorating ischemiareperfusion injury, resulting in tubular epithelial and vascular endothelial injury [11]. A large randomized clinical trial has demonstrated that patients undergoing cardiac surgery with CPB are more likely to have CSAAKI than those treated with surgery using a beatingheart (off-pump) technique [1]. The possible mechanism
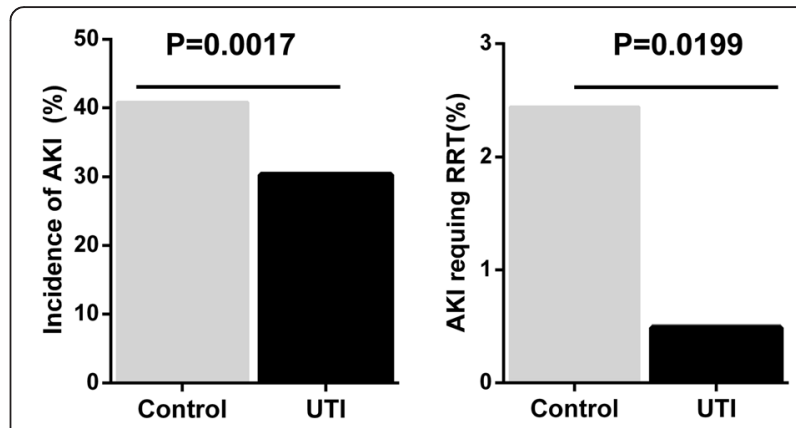

Fig. 2 Incidence of acute kidney injury (AKI) and AKI requiring renal replacement therapy between the control group and urinary trypsin inhibitor (UTI) group 
Table 2 Comparison of outcomes between the control group and the UTI group (propensity score matching)

\begin{tabular}{llll}
\hline Outcome & $\begin{array}{l}\text { Control group } \\
(n=409)\end{array}$ & $\begin{array}{l}\text { UTI group } \\
(n=409)\end{array}$ & $P$ value \\
\hline AKI, $n(\%)$ & $167(40.83)$ & $124(30.32)$ & 0.002 \\
RRT, $n(\%)$ & $10(2.44)$ & $2(0.49)$ & 0.020 \\
Death, $n(\%)$ & $11(2.69)$ & $4(0.98)$ & 0.068 \\
Length of ICU stay, d & $2.5 \pm 7.1$ & $2.0 \pm 2.09$ & 0.161 \\
Length of in-hospital stay d & $22.5 \pm 10.3$ & $21.6 \pm 7.4$ & 0.147
\end{tabular}

Abbreviations: $A K I$ acute kidney injury, RRT renal replacement therapy, UTI urinary trypsin inhibitor, ICU intensive care unit

may be associated with systemic inflammatory response, which occurs more frequently in patients who undergo CPB than in those treated with off-pump surgery [26]. The pathogenesis of systemic inflammatory responses involves multiple factors, such as surgical trauma, blood loss, transfusion, hypothermia, activation of the immune system, ischemia-reperfusion injury and endotoxemia [27]. The activation of humoral and cellular cascades results in an increase of proinflammatory cytokines, and eventually leads to cellular damage and organ injury [28].

Currently, the prophylactic pharmacologic agents aimed at attenuating the inflammatory response mainly include propofol, statins, and glucocorticoids [29]. The benefits of using corticosteroid prophylaxis as an anti-inflammatory agent in patients undergoing cardiac surgery with $\mathrm{CPB}$ remain controversial [30]. Although evidence indicates that corticosteroids are effective in reducing the risk of atrial fibrillation and mechanical ventilation duration [31], no difference in major outcomes was found, such as myocardial infarction, renal failure, and postoperative 30-day mortality [32, 33].

In the clinical practical setting, steroids should be prescribed cautiously for those patients with contraindications to steroids, such as peptic ulcer, diabetes mellitus, infection, and fracture. In contrast to steroids,

Table 3 Multivariable analysis determining covariate factors associated with AKI development

\begin{tabular}{|c|c|c|c|}
\hline Variable & Adjusted OR & $95 \% \mathrm{Cl}$ & $P$ value \\
\hline Male sex & 1.36 & $1.12-1.66$ & 0.002 \\
\hline BMI & 1.28 & $1.10-1.48$ & 0.001 \\
\hline History of hypertension & 1.58 & $1.23-1.96$ & $<0.001$ \\
\hline Insulin-dependent diabetes & 1.59 & $1.07-2.35$ & 0.021 \\
\hline RBCs transfused, $U$ & 1.09 & $1.06-1.12$ & $<0.001$ \\
\hline CPB duration $\geq 110 \mathrm{~min}$ & 1.38 & $1.13-1.68$ & 0.001 \\
\hline Mechanical ventilation $\geq 9 \mathrm{~h}$ & 1.01 & $1.00-1.02$ & 0.007 \\
\hline $\begin{array}{l}\text { Body temperature }\left(>38^{\circ} \mathrm{C}\right) \\
\text { after surgery within } 3 \text { days }\end{array}$ & 1.22 & $1.01-1.49$ & 0.044 \\
\hline Ulinastatin administration & 0.71 & $0.56-0.90$ & 0.005 \\
\hline
\end{tabular}

Abbreviations: $A K l$ acute kidney injury, $O R$ odds ratio, $\mathrm{Cl}$ confidence interval, $B M I$ body mass index, $R B C s$ red blood cells, $C P B$ cardiopulmonary bypass ulinastatin, a powerful protease inhibitor derived from human urine, has unique anti-inflammatory properties, which include inhibition of neutrophil elastase and other proteases and suppression of the production of cytokines, such as interleukin (IL)-6, IL-8, and tumor necrosis factor- $\alpha$, as well as endothelial leukocyte adhesion molecule-1 [34-38]. The possible side effects of ulinastatin, such as digestive symptoms, leukocytopenia, and hypersensitivity reactions, have rarely been observed in clinical studies [39-41].

On the basis of these properties of ulinastatin, it has been used to prevent postoperative complications and post-pump organ injury in patients undergoing cardiac surgery with CPB [42]. Nakanishi and coworkers [43] demonstrated that prepump administration of ulinastatin can suppress the elevation of postoperative IL- 6 and IL-8 in patients undergoing coronary artery bypass graft surgery with $\mathrm{CPB}$ in a prospective, randomized, doubleblind, placebo-controlled study. A meta-analysis of randomized controlled trials also indicates that ulinastatin can significantly decrease cytokine concentrations in patients undergoing cardiac surgery compared with those who received placebo [44]. Of note, a study of 60 subjects in Korea showed that ulinastatin administration has no cardiac or renal protective effects in patients undergoing aortic valve replacement with $\mathrm{CPB}$ [45]. In the study, the sample size of 30 patients in the UTI group and 30 patients in the control group was relatively small. Furthermore, the observation time points were only postoperative day 1 and day 2. The mean levels of $\mathrm{SCr}$, cystatin $\mathrm{C}$, and neutrophil gelatinase-associated lipocalin were employed to determine renal injury was present, instead of using the generally accepted Acute Kidney Injury Network or RIFLE (risk, injury, failure, loss, and end-stage kidney disease) criteria, making the study not so convincing. In addition, a letter to the editor in the same journal also raised concerns that the result should be interpreted with caution due to the relatively small sample size and the multifactorial causes of AKI [46].

Our data show that the administration of ulinastatin during $\mathrm{CPB}$ played a protective role in reducing the risk of AKI after cardiac surgery. Although the ICU and hospital lengths of stay seemed longer and mortality in the control group was higher, no statistically significant differences were found between the two groups. One possible reason is that the postoperative patients admitted to the ICU were then transferred to common wards on the second day as routine practice, unless the patients were in critical condition. Therefore, despite the fact that some patients developed AKI, a minor impact on the length of ICU stay resulted. The length of in-hospital stay was also influenced by the policy in our hospital, which limited the average length of hospital stay. 
Another aspect is that multiple factors including all kinds of complications, such as low cardiac output syndrome, bleeding, infection, and heart failure, can affect mortality and length of hospital stay. Further prospective randomized controlled trials with large sample sizes and perioperative administration of ulinastatin are warranted to confirm the protective role of ulinastatin in the development of CSA-AKI.

Our study has notable limitations. First, our study is a retrospective, single-center study, making it prone to bias. Second, due to the lack of urine output values, only creatinine was used to define AKI criteria. In addition, determining AKI on the basis of urine output was less than practical due to the urinary catheters' usually being removed about 2 days after surgery.

\section{Conclusions}

Our study shows that ulinastatin administration was associated with a lower incidence of CSA-AKI, suggesting that the administration of ulinastatin may be favorable for those patients undergoing cardiac surgery with $\mathrm{CPB}$.

\section{Key messages}

- Our results reveal ulinastatin administration was associated with a lower incidence of CSA-AKI using a propensity score methodology.

- Ulinastatin administration may play a protective role against the development of CSA-AKI in patients undergoing cardiac surgery with $\mathrm{CPB}$.

\footnotetext{
Abbreviations

AKI: acute kidney injury; BMI: body mass index; Cl: confidence interval; COPD: chronic obstructive pulmonary disease; CPB: cardiopulmonary bypass; CSA-AKI: cardiac surgery-associated acute kidney injury; ICU: intensive care unit; IL: interleukin; MAP: mean arterial pressure; OR: odds ratio; RBC: red blood cell; RRT: renal replacement therapy; SCr: serum creatinine; UTI: urinary trypsin inhibitor.
}

\section{Competing interests}

The authors declare that they have no competing interests.

\section{Authors' contributions}

CC designed the study, performed statistical analysis, interpreted the data, and drafted the manuscript. XW conceived the study, analyzed and interpreted the data, and drafted the manuscript. XX participated in the design of the study, performed the statistical analysis, and drafted the manuscript. YG participated in study design and helped to draft the manuscript. XC analyzed and interpreted the data and helped to draft the manuscript. XJ performed statistical analysis and drafted the manuscript. All authors read and approved the final manuscript.

\section{Acknowledgements}

We thank the surgeons and nursing staff of the Department of Cardiothoracic Surgery for providing consultation and useful information. This study was supported by Jiangsu Provincial Special Program of Medical Science (grant BL2014015). The funders had no role in study design, data collection and analysis, decision to publish, or preparation of the manuscript.

\section{Author details}

'Department of Nephrology, Nanjing First Hospital, Nanjing Medical

University, 68 Changle Road, Nanjing, Jiangsu 210006, China. ${ }^{2}$ Department of
Nephrology, Hangzhou First People's Hospital, Nanjing Medical University, 261 Huansha Road, Hangzhou, Zhejiang 310006, China. ${ }^{3}$ Division of Thoracic and Cardiovascular Surgery, Nanjing First Hospital, Nanjing Medical University, Nanjing, Jiangsu, China.

Received: 9 July 2015 Accepted: 23 January 2016

Published online: 17 February 2016

\section{References}

1. Garg AX, Devereaux PJ, Yusuf S, Cuerden MS, Parikh CR, Coca SG, et al. Kidney function after off-pump or on-pump coronary artery bypass graft surgery: a randomized clinical trial. JAMA. 2014;311(21):2191-8.

2. Parolari A, Pesce LL, Pacini D, Mazzanti V, Salis S, Sciacovelli C, et al. Risk factors for perioperative acute kidney injury after adult cardiac surgery: role of perioperative management. Ann Thorac Surg. 2012;93(2):584-91.

3. Brown JR, Kramer RS, Coca SG, Parikh CR. Duration of acute kidney injury impacts long-term survival after cardiac surgery. Ann Thorac Surg. 2010;90(4):1142-8.

4. Conlon PJ, Stafford-Smith M, White WD, Newman MF, King S, Winn MP, et al. Acute renal failure following cardiac surgery. Nephrol Dial Transplant. 1999;14(5):1158-62.

5. Robert AM, Kramer RS, Dacey LJ, Charlesworth DC, Leavitt BJ, Helm RE, et al. Cardiac surgery-associated acute kidney injury: a comparison of two consensus criteria. Ann Thorac Surg. 2010:90(6):1939-43.

6. Elmistekawy E, McDonald B, Hudson C, Ruel M, Mesana T, Chan V, et al. Clinical impact of mild acute kidney injury after cardiac surgery. Ann Thorac Surg. 2014;98(3):815-22.

7. Lassnigg A, Schmidlin D, Mouhieddine M, Bachmann LM, Druml W, Bauer P, et al. Minimal changes of serum creatinine predict prognosis in patients after cardiothoracic surgery: a prospective cohort study. J Am Soc Nephrol. 2004;15(6):1597-605.

8. Kolli H, Rajagopalam S, Patel N, Ranjan R, Venuto R, Lohr J, et al. Mild acute kidney injury is associated with increased mortality after cardiac surgery in patients with eGFR< $60 \mathrm{ml} / \mathrm{min} / 1.73 \mathrm{~m}^{2}$. Ren Fail. 2010;32(9):1066-72.

9. Mao H, Katz N, Ariyanon W, Blanca-Martos L, Adýbelli Z, Giuliani A, et al. Cardiac surgery-associated acute kidney injury. Blood Purif. 2014;37 Suppl 2:34-50.

10. Vives M, Wijeysundera D, Marczin N, Monedero P, Rao V. Cardiac surgeryassociated acute kidney injury. Interact Cardiovasc Thorac Surg. 2014:18(5):637-45

11. Rosner MH, Okusa MD. Acute kidney injury associated with cardiac surgery. Clin J Am Soc Nephrol. 2006;1(1):19-32.

12. Greenberg JH, Whitlock R, Zhang WR, Thiessen-Philbrook HR, Zappitelli M, Devarajan P, et al. Interleukin-6 and interleukin-10 as acute kidney injury biomarkers in pediatric cardiac surgery. Pediatr Nephrol. 2015;30(9):1519-27.

13. Gueret G, Lion F, Guriec N, Arvieux J, Dovergne A, Guennegan C, et al. Acute renal dysfunction after cardiac surgery with cardiopulmonary bypass is associated with plasmatic IL6 increase. Cytokine. 2009;45(2):92-8.

14. Scrascia G, Guida P, Rotunno C, de Luca Tupputi Schinosa L, Paparella D. Anti-inflammatory strategies to reduce acute kidney injury in cardiac surgery patients: a meta-analysis of randomized controlled trials. Artif Organs. 2014;38(2):101-12.

15. McBride WT, Prasad PS, Armstrong M, Patterson C, Gilliland H, Drain A, et al. Cytokine phenotype, genotype, and renal outcomes at cardiac surgery. Cytokine. 2013:61(1):275-84.

16. Thiele RH, Isbell JM, Rosner MH. AKI associated with cardiac surgery. Clin J Am Soc Nephrol. 2015;10(3):500-14

17. Jeong CW, Lee CS, Lee SH, Jeung HJ, Kwak SH. Urinary trypsin inhibitor attenuates liver enzyme elevation after liver resection. Korean J Anesthesiol. 2012;63(2):120-3.

18. Kim NY, Shim JK, Bang SO, Sim JS, Song JW, Kwak YL. Effects of ulinastatin on coagulation in high-risk patients undergoing off-pump coronary artery bypass graft surgery. Korean J Anesthesiol. 2013;64(2):105-11.

19. Zhang ZF, Yang N, Zhao G, Zhu L, Zhu Y, Wang LX. Preventive effect of ulinastatin and gabexate mesylate on post-endoscopic retrograde cholangiopancreatography pancreatitis. Chin Med J (Engl). 2010;123(18):2600-6.

20. Chen TT, Jiandong-Liu, Wang G, Jiang SL, Li LB, Gao CQ. Combined treatment of ulinastatin and tranexamic acid provides beneficial effects by inhibiting inflammatory and fibrinolytic response in patients undergoing heart valve replacement surgery. Heart Surg Forum. 2013; 16(1):E38-47. 
21. Zhang Y, Zeng Z, Cao Y, Du X, Wan Z. Effect of urinary protease inhibitor (ulinastatin) on cardiopulmonary bypass: a meta-analysis for China and Japan. PLoS One. 2014;9(12):e113973.

22. Lesperance R, Lehman R, Lesperance K, Cronk D, Martin M. Early postoperative fever and the "routine" fever work-up: results of a prospective study. J Surg Res. 2011;171(1):245-50.

23. Corral-Velez V, Lopez-Delgado JC, Betancur-Zambrano NL, Lopez-Suñe N, Rojas-Lora $\mathrm{M}$, Torrado $\mathrm{H}$, et al. The inflammatory response in cardiac surgery: an overview of the pathophysiology and clinical implications. Inflamm Allergy Drug Targets. 2015;13(6):367-70.

24. Abuelo JG. Normotensive ischemic acute renal failure. N Engl J Med. 2007;357(8):797-805.

25. Sutton TA, Fisher CJ, Molitoris BA. Microvascular endothelial injury and dysfunction during ischemic acute renal failure. Kidney Int. 2002;62(5):1539-49.

26. Jongman RM, Zijlstra JG, Kok WF, van Harten AE, Mariani MA, Moser J, et al. Off-pump CABG surgery reduces systemic inflammation compared with on-pump surgery but does not change systemic endothelial responses: a prospective randomized study. Shock. 2014;42(2):121-8.

27. Cremer J, Martin M, Redl H, Bahrami S, Abraham C, Graeter T, et al. Systemic inflammatory response syndrome after cardiac operations. Ann Thorac Surg. 1996;61(6):1714-20.

28. Paparella D, Yau TM, Young E. Cardiopulmonary bypass induced inflammation: pathophysiology and treatment. An update. Eur Cardiothorac Surg. 2002;21(2):232-44.

29. Kraft F, Schmidt C, Van Aken H, Zarbock A. Inflammatory response and extracorporeal circulation. Best Pract Res Clin Anaesthesiol. 2015;29(2):113-23.

30. Heyn J, Beiras-Fernandez A, Luchting B, Briegel J, Weis F. Inflammatory reactions and hydrocortisone in the setting of cardiac surgery: an overview. Cardiovasc Hematol Agents Med Chem. 2011;9(1):56-61.

31. Ho KM, Tan JA. Benefits and risks of corticosteroid prophylaxis in adult cardiac surgery: a dose-response meta-analysis. Circulation. 2009:119(14):1853-66.

32. Dieleman JM, Nierich AP, Rosseel PM, van der Maaten JM, Hofland J, Diephuis JC, et al. Intraoperative high-dose dexamethasone for cardiac surgery: a randomized controlled trial. JAMA. 2012;308(17):1761-7.

33. Cappabianca G, Rotunno C, de Luca Tupputi Schinosa L, Ranieri VM, Paparella D. Protective effects of steroids in cardiac surgery: a meta-analysis of randomized double-blind trials. J Cardiothorac Vasc Anesth. 2011;25(1):156-65.

34. Inoue K, Takano H, Shimada A, Yanagisawa R, Sakurai M, Yoshino S, et al. Urinary trypsin inhibitor protects against systemic inflammation induced by lipopolysaccharide. Mol Pharmacol. 2005;67(3):673-80.

35. Shu H, Liu K, He Q, Zhong F, Yang L, Li Q, et al. Ulinastatin, a protease inhibitor, may inhibit allogeneic blood transfusion-associated proinflammatory cytokines and systemic inflammatory response syndrome and improve postoperative recovery. Blood Transfus. 2014;12 Suppl 1:s109-18.

36. Aosasa S, Ono S, Mochizuki H, Tsujimoto H, Ueno C, Matsumoto A. Mechanism of the inhibitory effect of protease inhibitor on tumor necrosis factor alpha production of monocytes. Shock. 2001;15(2):101-5.

37. Nakatani K, Takeshita S, Tsujimoto H, Kawamura Y, Sekine I. Inhibitory effect of serine protease inhibitors on neutrophil-mediated endothelial cell injury. J Leukoc Biol. 2001;69(2):241-7.

38. Gao C, Huan J, Li W, Tang J. Protective effects of ulinastatin on pancreatic and renal damage in rats following early scald injury. Burns. 2009;35(4):547-52.

39. Karnad DR, Bhadade R, Verma PK, Moulick ND, Daga MK, Chafekar ND, et al. Intravenous administration of ulinastatin (human urinary trypsin inhibitor) in severe sepsis: a multicenter randomized controlled study. Intensive Care Med. 2014;40(6):830-8

40. Park KH, Lee $\mathrm{KH}$, Kim H, Hwang SO. The anti-inflammatory effects of ulinastatin in trauma patients with hemorrhagic shock. J Korean Med Sci. 2010;25(1):128-34.

41. Kanai T, Ishiwata T, Kobayashi T, Sato H, Takizawa M, Kawamura Y, et al. Ulinastatin, a urinary trypsin inhibitor, for the initial treatment of patients with Kawasaki disease: a retrospective study. Circulation. 2011;124(25):2822-8.

42. Song J, Park J, Kim JY, Kim JD, Kang WS, Muhammad HB, et al. Effect of ulinastatin on perioperative organ function and systemic inflammatory reaction during cardiac surgery: a randomized double-blinded study. Korean J Anesthesiol. 2013;64(4):334-40.

43. Nakanishi K, Takeda S, Sakamoto A, Kitamura A. Effects of ulinastatin treatment on the cardiopulmonary bypass-induced hemodynamic instability and pulmonary dysfunction. Crit Care Med. 2006;34(5):1351-7.
44. He S, Lin K, Ma R, Xu R, Xiao Y. Effect of the urinary tryptin inhibitor ulinastatin on cardiopulmonary bypass-related inflammatory response and clinical outcomes: a meta-analysis of randomized controlled trials. Clin Ther. 2015:37(3):643-53.

45. Oh SY, Kim JC, Choi YS, Lee WK, Lee YK, Kwak YL. Effects of ulinastatin treatment on myocardial and renal injury in patients undergoing aortic valve replacement with cardiopulmonary bypass. Korean J Anesthesiol. 2012;62(2):148-53.

46. Lema G. Ulinastatin treatment and renal injury in patients undergoing aortic valve replacement with cardiopulmonary bypass: a note of caution. Korean J Anesthesiol. 2013:64(1):91-2.

\section{Submit your next manuscript to BioMed Central and we will help you at every step:}

- We accept pre-submission inquiries

- Our selector tool helps you to find the most relevant journal

- We provide round the clock customer support

- Convenient online submission

- Thorough peer review

- Inclusion in PubMed and all major indexing services

- Maximum visibility for your research

Submit your manuscript at www.biomedcentral.com/submit
) Biomed Central 